Revista aSEPHallus de Orientação Lacaniana

Núcleo Sephora de Pesquisa sobre o Moderno e o Contemporâneo

ISSN 1809 - $709 \mathrm{X}$

\title{
Breves considerações sobre semblantes, violência e política
}

\section{Cleyton Andrade}

Psicanalista, Professor do Programa de Pós-Graduação do Instituto de Psicologia Universidade Federal de Alagoas, Maceió - AL

Doutor em Estudos Psicanalíticos pela UFMG

Autor do livro Lacan chinês - Poesia, ideograma e caligrafia chinesa de uma psicanálise,

10 lugar no Prêmio Jabuti 2016

E-mail: cleyton.andrade@ip.ufal.br

Resumo: O artigo discute relações entre formas do fenômeno da violência e concepções de política. Debate a violência constitutiva de semblantes que funcionam como aportes identitários; como reação ao insuportável da diferença; e decorrentes de uma política de estado. E por fim interroga por uma forma de pensar a política e a democracia como impossíveis, e consequentemente como modos de um pensamento que deva incluir o real. Palavras-chave: psicanálise; política; semblantes; violência.

\section{Brèves considérations sur le semblant, la violence et la politique}

L'article traite des relations entre les formes du phénomène de la violence et les conceptions de la politique. Un débat s'installe au sujet de la violence constitutive de semblants qui fonctionnent comme des contributions d'identité; en réaction à l' insupportable de la différence; et découlant d'une politique d'État. Et enfin, il refléchit sur une manière de penser la politique et la démocratie comme impossible, et par conséquent comme des modes d'une pensée qui doit inclure le réel.

Mots-clés: psychanalyse; politique ; des semblants; violence.

\section{Brief considerations on semblance, violence and politics}

The article discusses relations between forms of the phenomenon of violence and conceptions of politics. It debates the constitutive violence of semblances that function as of identity contributions; as a reaction to the unbearable of difference; and stemming from a state politics. And finally it reflects on a way of thinking about politics and democracy as impossible, and consequently as ways of a thought that should include the real.

Keywords: psychoanalysis; politics; semblances; violence. 


\section{Breves considerações sobre semblantes, violência e política}

Cleyton Andrade

Segundo a Organização das Nações Unidas, a grande massa de deslocados à força no ano de 2013 superou a marca de 50 milhões de pessoas. Em 2014, 86\% encontraram refúgio em países pobres e apenas $4 \%$ na Europa Ocidental. Limitando uma pequena área de travessia, de janeiro a outubro de 2015, mais de 500 mil cruzaram o mediterrâneo em busca de um modo de vida ou simplesmente tentando escapar da morte. Contudo, só nessa travessia, aproximadamente três mil vidas foram perdidas. Em Maceió, no nordeste brasileiro, há anos o índice de homicídios violentos é similar ao de um país em guerra, 66 mortos por 100 mil habitantes.

Maceió é a cidade mais violenta do Brasil, no que diz respeito às estatísticas de homicídios. O elemento formal dessa violência no nordeste não é o mesmo de outras regiões. E não se trata aqui da saída mais fácil encontrada por muitos que consideram o nordeste e o nordestino as causas permanentes para qualquer desvio do rumo iluminista. Por outro lado, dizer, como se diz habitualmente entre muitos habitantes de Maceió, que essa violência decorre da entrada do crack, apesar de sensato, é falso. Os semblantes nordestinos não são a causa, mas também participam da violência no nordeste.

A perspectiva liberal tem a premissa de que o efeito colateral das liberdades múltiplas se avizinha ao vício e à patologia, que naturalizam as ameaças ao espaço público. Os enunciados performativos atrelam os males sociais a uma causa precisa: um transtorno que desvia o indivíduo livre. Essa é a astúcia da razão liberal: a violência não é fruto da expansão do liberalismo, é desvio de alguns; a droga pode se tornar o elemento essencialista do mal, sobretudo se vier associada à pobreza ou à privação de condições e acessos. A estética do flagelo da droga participa da arquitetura que a política de estado reserva à vida nua.

A articulação significante num contexto libera/ tem efeitos de identificação e alienação nas inúmeras possibilidades de junção entre $\$$ e $a$, que o imaginário da realidade disponibiliza. A fórmula freudiana da fantasia precisa de três tempos: principalmente da peça faltante, inconsciente - "estou sendo espancado pelo meu pai"- para que seja reconstruído um elo entre os outros dois. Ela pode agir através de injunções implícitas que sustentam um modo de vida traduzível em costumes, articulando normas explícitas que não precisam ser seguidas com proibições que não devem ser reconhecidas explicitamente. Com isso, torna-se possível desrespeitar sistematicamente normas de trânsito e de convivência social ao mesmo tempo em que não se reconhece publicamente as violências políticas e passionais. Burlam-se as proibições escritas na lei e aceitam-se as proibições implícitas no discurso. Regras explícitas são violadas e, ao invés de terem efeitos caóticos, expressam e solidificam o espírito da comunidade. Uma transgressão dessa ordem não promove uma ruptura, ao contrário, parece reafirmar um vínculo, uma identidade. Para além das normas escritas ainda é possível a sobrevivência da identificação ao cabra macho e aos crimes que lavam a honra. 
Quando uma ausência é sistemática e não se apresenta como uma falta, mas como aquilo que se transmite numa série histórica, a violência pode se tornar intrínseca. Ela deixa de ser efeito de uma ausência de normatividade, para ser efeito de uma presença inscrita nos costumes.

A violência que vem imiscuída na realidade cotidiana pode ser um dos efeitos da invasão de algo inapreensível da fantasia, contribuindo para a formação de efeitos imaginários, principalmente quando ela reaparece inscrita na percepção da própria realidade.

Realidade esta, difícil de ser precisada sem equívocos. Freud (2014[1940]) considera insustentável a equiparação da percepção com a realidade como mundo externo. No Compêndio de Psicanálise, no capítulo sobre o Aparelho Psíquico e o Mundo Externo, Freud (2014[1940]) nos diz que enquanto o Isso é voltado para a obtenção de prazer, ao Eu cabe o encargo de adotar medidas de segurança. Se por um lado o Isso negligencia a autopreservação, o Eu não pode se dar esse luxo. Valendo-se do medo como sinal de alerta, o Eu procura manter sua integridade. Porém, tendo em vista que os traços mnêmicos podem tornar-se conscientes e adquirirem valências semelhantes à das percepções, principalmente se vierem por conexões associativas com restos de fala, resulta que o reconhecimento da realidade não se desvencilha de uma possível indistinção. Resolver o que se apresenta como indiscernível seria a função do teste de realidade.

Frente ao funcionamento do aparelho psíquico é insustentável uma noção uniforme da realidade como uma unidade orgânica. A importância da realidade erguida por Freud à condição de ser uma das três instâncias, juntamente com o Isso e o Supereu, que exigem soluções do Eu, não deixa de refletir certa ambiguidade e relega à realidade o peso incontornável de permanecer muito menos objetiva que a razão empirista pudera sonhar.

Por outro lado, pode haver igualmente uma violência em que essa invasão de algo inapreensível da fantasia se manifesta sob a forma de semblantes reconhecidos socialmente, e com isso, ao invés de chocarem entre si na forma de horror, assustando e amedrontando, passariam a fazer parte dos costumes e dos modos de vida. Uma violência assim seria mais silenciosa na medida em que estaria impressa e impregnada nos costumes e por isso menos perceptível em sua face violenta; deixaria de ser bizarra e amedrontadora para ser um estranho familiar. Violências sob o regime do desconhecimento, tais como condomínios fechados feitos à base de muros e portões erguidos em vias públicas sem autorização, cercas em calçadas improvisando garagens e impedindo a circulação de pedestres, leis estaduais de uma escola livre embora inconstitucional, desrespeito sistemático às leis de trânsito, dentre outras formas de convívio social em que o espaço do outro é largamente desconsiderado. Nada disso, contudo, é interpretado como violência. Ao contrário. Faz parte do dia-a-dia e dos hábitos. Uma violência absorvida pelos costumes, ou costumes que perduram sob um princípio de violência.

Em um tipo de invasão, o real da fantasia ganha contornos imaginários ao penetrar a realidade com horror e intolerância. No outro, ela adere ao funcionamento da máquina significante e assume formas mais sutis e toleráveis, fazendo parte da cultura "local". Tratar-se-ia de reconhecer 
o real da fantasia no que parece ser uma fiç̧ão simbólica, reconhecendo uma violência no que é considerado costume ou modo de gozo.

O excesso na inobservância às normas escritas pode expressar um real da violência que não é concebido como tal, mas nem por isso desprovido de efeitos. Esse excesso não é captado pelas pesquisas, pois o regime de visibilidade destas apreende apenas um de seus produtos sintomáticos devido à sua reversibilidade em número de homicídios e ocorrências policiais. Afinal, a violência que é inerente a alguns semblantes não pode e nem deve ser medida e muito menos vista. Entretanto, seu excesso transborda para outros modos de expressão, sustentando formas sutis de uma violência sistêmica que não é percebida como tal.

Isso talvez nos mostre como uma violência identitária pode naturalizar a expressão "aqui é assim mesmo", num consentimento quase melancólico em torno de uma perda que não pode ser identificada nem ser objeto de luto. Onde rupturas sucessivas e sistemáticas do laço podem fundar e sustentar outro tipo de pacto cujo princípio está longe de ser o da igualdade. A ruptura sistemática se inscreveria como um novo pacto absorvido como formador de um semblante que funcionaria como suplemento de uma identidade cultural. $S_{1}$ que não reenvia a $S_{2}$, mas funciona como ponto de ancoragem identificatória e com efeitos sobre os modos de vida. Uma violência constitutiva de um modo de gozo.

Há várias maneiras de abordar a violência nas cidades. Ela pode envolver questões de intolerância, racismo, desigualdade, exploração, injustiça, dentre outras. Encontrar uma causa para a violência, dar-lhe uma forma diante de sua opacidade e também uma essência que encarne o mal na sociedade, pode ser mais do que encontrar uma resposta, pode ser um artifício da astúcia da razão liberal. Há um real na violência que não pode ser retirado da operação, inclusive porque ele pode fazer do modo de vida uma de suas formas de retorno e insistência, o que torna difícil dar-Ihe uma definição objetiva.

Todavia, pensar a violência restringindo-a àquilo que está fora da articulação significante implica numa equivalência forçada com a passagem ao ato. Isso é verdadeiro no Lacan (1998[1948]) do caso Aimèe, mas está longe de ser sua condição de possibilidade. Interrogar as formas que esse fenômeno se manifesta nos permitiria rever tal equivalência. Tratar a violência apenas como passagem ao ato incorre no risco de avizinhar o tema à psicopatologia, erro que se não é cometido pela psicanálise lacaniana, é amplamente aceito por algumas interpretações substancialistas. Relegar esse fenômeno ao mero estatuto de um desvio ou transtorno, é o que é feito historicamente por diversas expressões normativas do pensamento conservador. O paradoxo é que, de um lado, desumaniza a loucura, e de outro, desresponsabiliza o sujeito, ao mesmo tempo em que isenta qualquer participação da política de Estado no fenômeno da violência. A conta acaba sendo reportada a uma entidade sem forma, um transtorno sem sujeito, ou àqueles que despidos de uma vida que de fato seja política ou politizável se tornam, por não terem direitos, o lugar de repouso dessa culpa. 
Tanto melhor, se os dois fatores se encontrarem, ou seja, se o transtorno for, na verdade, uma prerrogativa natural da vida nua.

A relação feita por Lacan (1998[1948]) a respeito da agressividade e discurso de um lado, e violência como fora do discurso, do outro, pode ser entendida, em 1948, como uma resposta aos pós-freudianos. Eles estavam embaraçados com a dificuldade clínica no manejo com obsessivos e se entregaram a hipóteses mirabolantes acerca de fixações anais, resistências, reação terapêutica negativa, para ficarmos em alguns exemplos. Teorizaram o que acreditavam ser a agressividade desses pacientes.

Dizer que a agressividade esteja presente como um dado de estrutura no discurso e a violência como um contraponto, talvez sirva menos para definir esta do que para retificar o discurso pós-freudiano rumo ao retorno à Freud. Lacan (1998[1948]) procurava dizer que não se tratava de uma resistência ou reação terapêutica negativa, nem uma relação com o objeto anal, mas sim de algo correlato à identificação narcisista e à estrutura paranoica do eu. Uma intervenção sobre o desvio de alguns não pode justificar o desvio de outros. Uma resposta aos pós-freudianos poderia ser elevada ao estatuto de enunciando canônico sobre a violência?

Cabe perguntar se a tese da antinomia entre palavra e violência se sustenta diante dos fenômenos de antissemitismo, do fundamentalismo religioso, dos ataques de Israel para fazerem cumprir ora a palavra oficial que fundou um Estado, ora a palavra divina que designa o povo escolhido. Seriam eles exemplos da violência que é fruto de uma demissão da palavra? Ou seria exatamente o contrário? Seriam formas possíveis de uma violência que se justifica pela palavra, tanto política quanto religiosa? Creio serem exemplos de uma violência fora do contexto da passagem ao ato, fruto tanto de significantes mestres, quanto de articulações significantes, ou até de um campo de imagens e de semblantes quase inegociáveis, sobretudo quando são suporte para representações identitárias.

Em diversos países a dimensão da intolerância é elevada a níveis em que o confronto se torna cada vez mais difícil de evitar. Multiplicam-se os grupos que externam uma impossibilidade fundamental que encarna um obstáculo visto como intolerável. Seja em nome da democracia ou do fascismo autoritário que restabeleça a ordem miticamente perdida, seja na defesa da sustentação de um estado de exceção justificado pela emergência econômica, ou em nome de um desconhecimento do fim de um sonho igualitário, ou mesmo da tautologia dos direitos daqueles que têm direitos, o ódio parece pedir passagem para se afirmar com um dos afetos políticos e sociais mais importantes. O ódio e por extensão a violência como uma de suas faces, cada vez parece mais legítimo e justificável quando se trata não da defesa da integridade, mas de assegurar-se dos referentes estáveis da própria identidade ameaçada pela estranheza suscitada na presença do diferente. Para a ameaçadora multiplicidade e diversidade de liberdades, a normatividade de uma única liberdade. Para a constrangedora polivalência dos modos de gozo, o ordenamento de um modo 
de gozo autorizado e prescrito. Daí toda uma preocupação em torno de uma política da diferença, da tolerância, elevando o tema do amor a um lugar de destaque.

Mesmo que ela esteja presente, como, por exemplo, no fenômeno de refugiados venezuelanos no norte do Brasil, não é a principal forma de violência que assusta os brasileiros. Até bem pouco tempo atrás, venezuelanos e brasileiros cruzavam a fronteira em ambas as direções por comércio ou quaisquer outras coisas de uma vida cotidiana. Em função da crise na Venezuela, homens e mulheres que circulavam nesse mesmo espaço, agora na condição de refugiados, passam a receber não só outro tratamento, mas inclusive outros nomes. As venezuelanas passaram a ser chamadas de ochenta, em referência ao valor de oitenta reais que, segundo alguns brasileiros, elas cobrariam por programas sexuais. Diante disso se justificaria uma pergunta aparentemente ingênua: o que faz de uma mulher venezuelana, uma mulher e uma venezuelana? O que se verifica nessa passagem de venezuelana para ochenta senão o desvelamento da insuficiência da aparente equivalência entre homem-direito-cidadão? Hannah Arendt e Giorgio Agamben já chamaram a atenção para a condição de paradigma da figura do refugiado, que expõe o envelhecimento de alguns dos fundamentos sobre os quais se assentam algumas noções modernas da política.

As modalidades de violência mais comuns no Brasil passam pelas manifestações homofóbicas, pelos clubes da luta que se vestem de torcidas organizadas, pela violência de gênero ainda velada, pelo preconceito em aeroportos quando classes econômicas ainda se incomodam de dividir espaço com alguns refugiados nascidos no mesmo Estado-nação. Ou até em polarizações pseudopolíticas que ilustram charges de novas e risíveis tentativas de uma nosologia, que encontra na "esquerdopatia" um bom e bizarro exemplo. Mas, sobretudo, pela violência a homens jovens negros pobres da periferia. A intolerância e a segregação estão expressas em algumas formas da violência brasileira, mas não bastam para explicá-la.

No filme Elysium (2013) do diretor Neill Blomkamp, os segregados da Terra queriam ocupar o condomínio de luxo que dá nome ao filme, enquanto aqui bem mais perto, jovens da periferia tornaram popular o funk ostentação. Essa manifestação que, por falta de nome melhor, chamamos popular - afinal, o que é o povo? -, faz uma crítica interessante. Ela evidencia que mesmo que uma parte da violência urbana pode até ser um retorno do gozo da droga, outra parte expressiva se reverte em objetos de ostentação. O lado sutil da intolerância e da segregação está na resposta sintomática daquele que foi segregado. Ele não tolera o que nele é intolerável e segregado. $\mathrm{O}$ que fez dele o alvo de uma violência sem rosto, é recusado por ele mesmo, e por vezes pode vir sob a forma de outra violência que tem cara e com isso aparece nas estatísticas. Mas pode reaparecer como uma afirmação que recusa a negação. Tal recusa de ser vítima da sociedade pode se inscrever no ato violento, roubando e mantando no Outro o que lhe parece seu por direito. E pode aparecer também como uma celebração totêmica de comunhão com a Casa Grande. A violência não como o gesto da vítima, mas como o ato de resistência, de recusa dessa posição e daquilo que o tornou 
segregado. Aquele que foi despido de direitos e oportunidades não pode ser confundido com o agente da violência, nem mesmo com a vítima.

A democracia moderna, que não é a grega, não é o governo do povo pelo povo, é a recusa sistemática do princípio anárquico e ingovernável da democracia. É a contraditória exigência de títulos para governar, quando na verdade seu único fundamento deveria ser a absoluta ausência de título e fundamento. Para Rancière (2014) a democracia não é um regime político. Tampouco é uma forma de sociedade a ser governada ou o governo da sociedade. Ela é o princípio da ingovernabilidade. O impossível de governar. Nesse ponto ele se aproxima de Freud.

Não é um princípio ingovernável que necessariamente conduza a figuras da impotência. Ao contrário, parece muito mais com uma condição de possibilidade sobre a qual qualquer governo deveria ser fundamentado. O poder do povo em jogo na democracia não se confunde com o poder da multidão, mas sim com as bases do governo de qualquer um, de uma indiferença irredutível entre capacidades ou valores para governar ou para ser governado. Esse seria um dos principais fundamentos da política: a ausência de fundamento. Um referente vazio, não qualificável.

Considero importante essa via aberta pelo trabalho de Rancière (2014), por permitir pensar a democracia como ingovernável, um impossível, uma vez que viabiliza uma aproximação com a noção de real em Lacan para pensar a política. Dizer que a política é sem representação, um princípio anárquico, é dizer que partimos de uma referência vazia. Com isso, o governo ou poder do povo, nesse caso, não significa uma valência positiva. Não se pode associar o povo a um valor identificável a um grupo populacional nem a uma expressão aglutinadora de uma coletividade. Seria em vão que se buscaria uma virtude inata no cerne dos enunciados valorativos e emancipatórios do poder do povo, semelhante a um regime regulatório como resistência às formas do biopoder. A começar porque esse poder do povo não é um todo homogêneo que se possa representar. $O$ regime da representação e a expectativa de uma adequação funcional se chocam com a heterotopia própria de uma sociedade não igualitária da qual esse povo é o testemunho, mesmo não sendo a testemunha. Afinal, insisto que a vida nua não conta para o discurso jurídico que daria lugar à figura da testemunha.

O povo é o que há de mais irrepresentável na democracia e na política. O povo, como já disse, não é a população epidemiologicamente determinável, ou localizável geograficamente. Portanto, uma democracia que se nomeia representativa, não produz um enunciado constatativo nem ao menos um pleonasmo. É a descaracterização moderna do conceito de democracia. Qualquer regime representativo e consequentemente representacional opera uma subtração mais do que uma inclusão. Afinal, não tem como incluir uma parte que não cessa de não se escrever, que também pode ser chamada de povo. Seja partindo de Agamben (2015[1996]), que destaca que povo é o nome da minoria não escrita, irredutivelmente não inscrita, ou de Rancière (1998), para quem o povo nomeia a ausência de título, de fundamento, e de qualidade para governar ou ser governado, podemos compreender o povo como um nome daquilo que é inominável para uma política 
identificada às funções de estado. Há uma convergência quase espontânea entre povo e vida nua. Pode se dispor tanto de uma quanto do outro, uma vez que nenhum deles de fato conta.

Enfim, falo da democracia como a irrupção de um excesso que produz efeitos traumáticos. Por outro lado, existem semblantes de democracia que visam dar um tratamento ao furo insuportável. Esse tratamento performativo das imagens e significantes transforma o excesso numa avidez consumista. O indivíduo egoísta, hedonista, se torna o consumidor ávido por produtos do mercado, gadgets, drogas, medicamentos, direitos, liberdades, e quaisquer outras mercadorias que possam ser compradas num mercado livre. Torna-se um consumidor seja lá do que for. Tal como o aluno que resolve seu problema com o saber e o não-saber através das avaliações de professores. As instituições de ensino valorizam cada vez mais os instrumentos de avaliação dos professores pelos alunos, para darem mostra de quão elas são democráticas, horizontais e fiéis ao código do consumidor.

Em suma, o consumidor ávido se tornou o homem democrático (Rancière, 2014). É aquele mesmo que nada quer saber sobre o pathos no saber, ainda mais porque sabe muito bem seus direitos de consumidor. É fácil constatar que a diversidade da liberdade foi substituída por uma única liberdade: a do mercado, a do comércio. Enquanto que a noção de igualdade deixou o lugar do $\mathrm{S}_{1}$ revolucionário para se tornar a igualdade normativa do contrato. Para Rancière (1998), a igualdade foi reduzida à igualdade mercantil que vela a exploração cínica e brutal de uma desigualdade fundamental. $\mathrm{O}$ que se revela é que, sob a imagem do reino da igualdade propagada, repousa uma fundamental desigualdade e o reino da exploração. A igualdade não é mais que a troca igual da contratualidade mercantil.

O então consumidor ávido por satisfações privadas é a verdade do homem democrático. Vida nua e homem democrático não são figuras opostas. Penso que há uma confusão nesse par. 0 homem democrático, entendido como o consumidor ávido, se apresenta como uma figura emancipada da vida nua, como se passasse a gozar de direitos e de uma vida política.

O funk ostentação nos mostra que a ostentação não é um antidoto para a ausência de direitos e o estatuto despolitizado da vida. Ela, a ostentação, pode ser no máximo uma violência e tentativa de recusa de uma vida nua, que já é o objeto por excelência do biopoder e da biopolítica, e no mínimo outro semblante que atenua sem emancipar. O que o funk ostentação ostenta, tal como outras formas de gozo que partam do mesmo princípio, é uma forma de semblante e de gozo que busca ser reconhecida como forma de vida, como algo que possa contar em meio à vida nua que não conta. Os moradores revoltosos da Terra que queriam ocupar Elisium recusavam a vida nua, mas antes de emergirem como sujeitos de uma forma de vida politizável, procuravam o acesso a outras formas de gozo identificáveis a objetos consumíveis. Esse é o engodo do homem democrático frente à vida nua.

O real como impossível se apresenta também na esfera social como algo foracluído do espaço político que retorna sob a forma do ato violento. Um exemplo foram as manifestações de 
junho de 2013. Uma resposta do real, coletiva, como efeito de sucessivas foraclusões no espaço público e político. Tentou-se, algum tempo depois, restituir a ordem no simbólico através de significantes como Black Blocs e "baderneiros", na busca de sentido e significação que pudesse aplacar a desordem do real e o impossível que se fez presente ali. A astúcia da razão não nega a violência, ao contrário, reafirma-a e destaca-a como estratégia de sua própria manutenção. Afirmando a violência dos black blocs e judicializando-a, procura-se obliterar uma resposta do real que seria uma das formas de conceber o ingovernável da democracia. Os ideais republicanos e liberais encontram formas de prescrever a norma de tal modo que cada coisa tenha seu lugar e sua função. A rua é lugar de circulação, não de aglomeração e manifestações. Portanto, cada transeunte que não transita é baderneiro por desregular a regra. A desordem do real próprio à democracia, antes de ser nomeada pelos significantes mestres do impedimento, foi atribuída à violência de alguns grupos. De um modo ou de outro, o que se visa, é uma operação de sutura do real no social e na política.

Os Estados-nação formados antes do século XVIII consolidaram o conceito de cidadania em torno da lei civil e não de costumes e religião. Por outro lado, os Estados mais jovens formados após o século XIX tiveram na pureza étnica uma legitimação contra o imperialismo de nações mais poderosas. Cada vez mais vemos a possibilidade de valores universais perderem espaço para ameaças imaginárias a particularismos culturais. O medo ao estrangeiro em nome de um monoculturalismo alimenta imagens que já poderiam ter sido esquecidas, como a de um cidadão que retoma o semblante da Ku Klux Klan para protestar contra a chegada de mais um grupo de refugiados.

Seja pela chegada de algum elemento perturbador que rompe uma harmonia imaginária, como quando se atribui à chegada do crack em Maceió para justificar o alto índice de violência, ou à chegada do estrangeiro de outra etnia, fé e costumes, seja para ruptura de um pacto, encontramos nos semblantes um ponto aglutinador desse estrangeiro antes de considerá-lo como Unheimlich. Primeiro ele é identificado como uma unidade orgânica essencialista, mas sempre diferente e outro. Depois, é aquilo que horroriza e assusta.

Parece haver, mesmo que parcialmente, fora questões políticas, históricas ou socioculturais, uma semelhança com o regime que regulava as relações entre semblante e real no primeiro Lacan. O real que Lacan encontrou em Levi-Strauss é, em última instância, um real dominado pelo semblante. Pode ser repartido em elementos que podem ser significantizados, submetidos a uma ordem simbólica e ao saber. É um real transmutável em significantes. Um real relativamente dócil à primazia do ordenamento simbólico do Nome do Pai. Há um modo de pensar a democracia e a política, por exemplo, como objetos do pensamento a partir de ordenamentos simbólicos e de regimes representacionais. Estamos falando de uma concepção de democracia e de política traduzíveis em formas institucionais em que o real é dominado pelo semblante. 
Ricardo III, de Shakespeare (1995), por crer ser desprovido de qualidades que o permitam partilhar a norma social e atender às expectativas amorosas, atribui ao real estruturalista do seu corpo a justificativa e autorização para fazer toda uma série de trapaças e hostilidades. A primazia do semblante de coxo, feio, malformado pela natureza legitima imaginariamente os seus atos. 0 sentido que ele encontra em sua imagem é o suporte para a violência.

Mas eu, que não fui talhado para as habilidades esportivas, nem para cortejar um espelho amoroso; que, grosseiramente feito sem a majestade do amor para pavonear-me diante de uma ninfa de lascivos meneios; eu, privado dessa bela proporção, desprovido de todo encanto pela pérfida natureza; disforme, inacabado, enviado por ela antes do tempo para esse mundo dos vivos; terminado pela metade e isso tão imperfeitamente e fora de moda que os cães ladram para mim quando paro perto deles, pois bem, eu, neste tempo de serena e amolecedora paz, não acho delícia em passar o tempo, exceto espiar minha sombra no sol e dissertar sobre minha deformidade! E assim, já que não posso mostrar-me como amante, para entreter estes belos dias de galanteria, resolvi portar-me como vilão e odiar os frívolos prazeres deste tempo. (Shakespeare, 1995, p. 580)

Diante do real do corpo e da significação de um "eu privado" de diversos semblantes caros à sua época, ele acaba por se valer de outro semblante que lhe serve como uma tradução possível, bem como de um modo de gozo correspondente: vilão.

O real do corpo se vê operado pelas leis da imagem e da linguagem. Com Ricardo III podemos pensar um semblante que reúne efeitos de sentido e de significação que fazem do real nada mais que algo dominado e regulado pelo semblante. O semblante estruturalista de Ricardo III é seu salvo conduto para agir com vilania. $O$ sentido que ele encontra em sua própria imagem o autoriza e justifica a violência. $\mathrm{O}$ incômodo seria pensar tanto uma concepção de democracia, quanto de política, a partir do exemplo de Ricardo III. Se assim o for, estaríamos diante de formas e procedimentos em que o real é racional, é traduzível em significantes, em enunciados normativos, performativos. Uma democracia pensada a partir da primazia e da adequação do semblante sobre o real pode ser entendida como uma democracia representacional, mais do que representativa. Algo que, de um modo ou de outro, escamoteia ou foraclui o real e seus efeitos. Não seria exagero encontrar na violência social, tanto das estatísticas quanto daquelas implicadas direta ou diretamente na questão dos refugiados, o retorno no real disso que o ordenamento ou tradução dos semblantes refutou.

Tal aposta de que o semblante pode dominar e regular o real é a mesma na qual se apoia a convicção conservadora das diversas expressões do monoculturalismo. Em que o bispo Lászlo KissRigo se apoiaria, senão nesse semblante estruturalista de Ricardo III, para dizer xenofobicamente 
que "Não são refugiados, isto é uma invasão aos gritos de Allahu Akbar! Eles querem tomar posse e ameaçar os valores cristãos universais da Europa"? A que tipo de conjunto de ações e medidas se autorizaria diante de uma constatação como essa? Se o modo de vida ou modo de gozo do outro me é estranho, posso fazer do meu gozo a lei e a norma a ser prescrita. Sendo assim, medidas de manutenção de uma identidade são bem-vindas, bem como intervenções ortopédicas sobre a diferença são naturalmente autorizáveis.

As referências que também partem da primazia do significante e do simbólico, do regime central do falo e do Édipo, não são apenas insuficientes para o pensamento dessas formas de violência, são seu próprio argumento. Em torno desses centros é que gravitam as condições de possibilidade para se pensar num primado do semblante sobre o real. Tornar essa questão pensável dentro de outro regime de pensamento exige uma lógica para além do falo e do Édipo. É a inversão feita e direcionada pelo próprio Lacan, desde o final dos anos 1960, mas sobretudo a partir dos anos 1970.

Essa inversão que torna o semblante não mais que um mero semblante dentre outros tantos possíveis, pode conter algo da possibilidade de uma resistência ao totalitarismo dos Estados e cidadãos adeptos do monoculturalismo. Talvez seja preciso pensar a viabilidade de se pensar em um novo universal que esteja à altura de discutir valores universais que levem em conta que semblantes não passam de semblantes. Ao contrário de serem considerados como uma identidade conferida pela natureza numa perspectiva essencialista. Uma inteligibilidade de um universal que acolha 0 semblante não como uma tradução do real, mas como aquilo que se inscreve ali onde no real não há lei, nem sentido, nem saber. Que conviva com a ideia de que é o real como impasse de formalização que determina o que pode se inscrever como semblante.

Se for possível dizer que o semblante, assim como a ideologia, excede o pensamento, seria preciso interrogá-lo a partir de uma forma de intervenção que aponte para esse desacordo essencial entre o que dele nos afeta e aquilo que nosso pensamento pode dominar.

O problema estrutural que atravessa a política, assim como a violência, é que todos fomos roubados. Todos fomos vítimas de um roubo e a fantasia é a articulação fundamental disso. Ela é a encenação e a narrativa de como o sujeito teve seu gozo roubado. Isso não quer dizer que a verdade da violência é a fantasia, nem mesmo que a segunda justifique a primeira. A psicanálise não recua diante da afirmação da responsabilidade do sujeito.

E se fossem saneadas as formas de segregação? Essa utopia não é uma alternativa, pois não passa de uma velha opção populista que alimenta a violência sistêmica, na medida em que sua retórica sustenta um sofisma: a promessa de que o real não implica a impossibilidade. Por isso, é preciso uma política que leve em conta o real como impossível, que considere o obstáculo como intrínseco, de estrutura, e não meramente formal, positivo e exterior. Se Lacan (1998[1948]) disse que é muito difícil ser violento, quero crer que esta política que leve em conta o real como impossível 
seja a encarnação da real violência. Não aquela privada que incide nos corpos, nas cidades, no espaço público ou privado, mas que incida no modo tradicional de pensar e fazer política.

\section{Referências Bibliográficas}

Agamben, G. (2015). Meios sem fim: notas sobre a política. Belo Horizonte: Autêntica Editora, (Trabalho original publicado em 1996).

Badiou, A. (1998). Compêndio de metapolítica. Lisboa: Instituto Piaget.

Blomkamp, N. (Direção). (2013). Elysium [Filme cinematográfico]. EUA: Sony Pictures.

Freud, S. (2014). Compêndio de psicanálise e outros escritos inacabados. In: Obras incompletas de Sigmund Freud (Vol. 3, pp. 11-195). Belo Horizonte: Autêntica Editora (Trabalho original publicado em 1940).

Lacan, J. (1998). A agressividade em psicanálise. Escritos (pp. 104-126). Rio de Janeiro: Jorge Zahar

Ed. (Trabalho original publicado em 1948).

Rancière, J. (2014). Ódio à democracia. São Paulo: Boitempo.

Rancière, J. (1998). Nas margens do político. Lisboa: KKYM.

Shakespeare, W. (1995) Ricardo III. Obras Completas. V. III. Rio de Janeiro: Nova Aguilar.

Citacão/Citation: Andrade, C. (mai. a out. 2017). Breves considerações sobre semblantes, violência e política. Revista aSEPHallus de Orientação Lacaniana, 12(24), 123-134. Disponível em www.isepol.com/asephallus. doi: 10.17852/1809-709x.2019v12n24p123-134.

Editor do artigo: Tania Coelho dos Santos.

Recebido/Received: 24/09/2016 / 09/24/2016.

Aceito/Accepted: 18/10/2017 / 10/18/2017.

Copyright: (C) 2013 Associação Núcleo Sephora de Pesquisa sobre o moderno e o contemporâneo. Este é um artigo de livre acesso, que permite uso irrestrito, distribuição e reprodução em qualquer meio, desde que o autor e a fonte sejam citados/This is an open-access article, which permites unrestricted use, distribution, and reproduction in any medium, provided the author and source are credited. 